\title{
AN EXPERIMENTAL STUDY OF THE COARSE DROPLETS FORMATION
}

\author{
Ondřej BARToš**, Lucie MĚŠŤTanová
}

\author{
Czech Technical University in Prague, Technická 4, Prague 6, Czechia \\ * corresponding author: ondrej.bartos@fs.cvut.cz
}

\begin{abstract}
The paper introduces the first results from a new steam/air wind tunnel built in order to study the coarse water droplets in steam turbines and their formation. The wind tunnel was designed with the aim to have a testing facility with similar flow conditions for the study of liquid films as found in steam turbines. The tunnel is equipped with common devices for the measurement of the flow and for the analysis of the diameter distribution of the droplets. Two measurements methods were used for the measurement of the droplets size, photogrammetry and light scattering. The liquid film is artificially produced on an airfoil placed in the nozzle and liquid is pumped by a dosing pump on the surface of the airfoil. Coarse droplets formed from the liquid films have a negative effect on the reliability and efficiency of the turbines due to the erosion and corrosion by the droplets impact on the leading edges of the blades.
\end{abstract}

KEYwORDs: Steam turbine, coarse droplets, liquid films.

\section{INTRODUCTION}

The atomization of liquid is a widely studied problem for spray nozzles and in the field of aerosol research. A similar phenomenon is known in steam turbines but mostly with undesirable effects, coarse droplets have a negative effect on the reliability and efficiency of steam turbines. The study of the formation and evolution of water droplets in turbines at high velocity plays an important role in the continuous effort to enhance energy production and decrease its environmental impact. There are other applications where liquid films are present on a moving body, for example on the trailing edge of wings, propellers and blades and the result of this study could be useful. Nevertheless, due to the wide range of applications the project is focused on the conditions in steam turbines. In the long term the authors of the paper are concerned with experimental research into the liquid phase structure in steam turbines [1].

Two groups of water droplets are present in steam turbines. The nucleation of the droplets and their subsequent growth through condensation are responsible for the presence of very fine droplets. The expected range of fine droplets is from $50 \mathrm{~nm}$ to $800 \mathrm{~nm}$. Coarse droplets are formed by the disruption of water films on the blades and casing surfaces in the low-pressure turbine stages. The present knowledge of the coarse water flow field and the size distribution of the droplets in turbines is still insufficient. The range of the diameters of the coarse droplets is very wide, from a few micrometers to one millimeter. The coarse droplets are responsible for some unfavorable effects like additional energy losses and a reduction in the lifetime of the blades (fig. 1). A better understanding of the formation of coarse droplets and their properties may provide future enhancements for the steam turbine and other similar applications. Previous measurements of coarse droplets directly in the steam turbine made it necessary to build an experimental tunnel for the study of the formation of the droplets and their properties [2] in the laboratory.

The break up of liquid film in steam turbines is also connected with another interesting effect known as "charge separation". The electrostatic charge in steam turbines is mainly connected with the existence of an electrostatic potential between the stator and the rotor of the turbine. The potential can cause bearings damage due to a short circuit of the current and the subsequent operational failure of the turbines. The first to describe the problem was T. Sauer [3], who measured the current between the rotor and the ground for different load and operational states. He expected that the origin of the electrical current arose from the similar phenomena described by Lenard [4, who had observed that small droplets in the vicinity of waterfalls have an electric charge. Sauer expected that the current was dependent on the turbine load and chemical properties of the steam and he expected that the positive current was connected with the erosion of the blades. The study of this electrostatic phenomena is the second main goal for the new wind tunnel. This note is added for the purpose to mention such the effect which can be connected with the coarse droplets formation and its possible influence on the erosion and corrosion due to the droplets discharge.

\section{Description of THE NEW TUNNEL}

The motivation for building the new wind tunnel arises from the previous measurement [5] of coarse droplets in the steam turbine under operational conditions. The measurement was performed in three power stations in Czechia. In all steam turbines the amount 


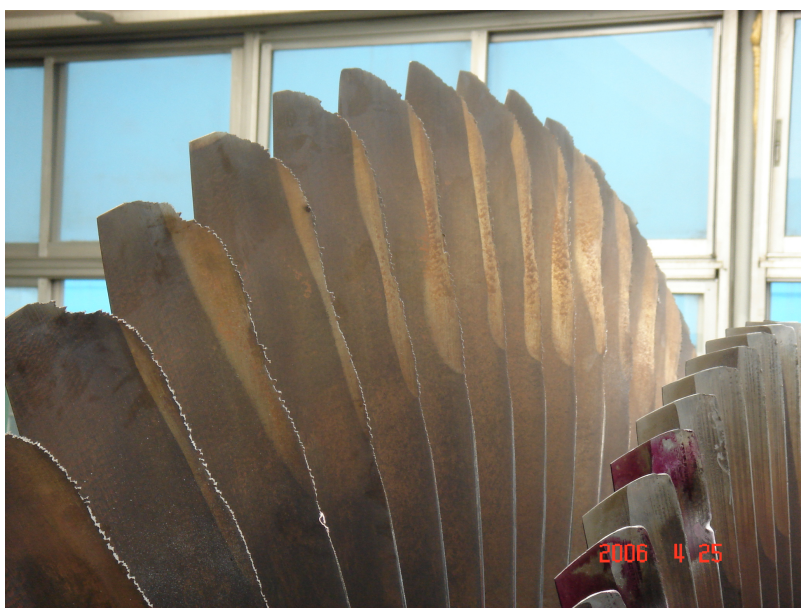

Figure 1. Extremely damaged turbine blades.

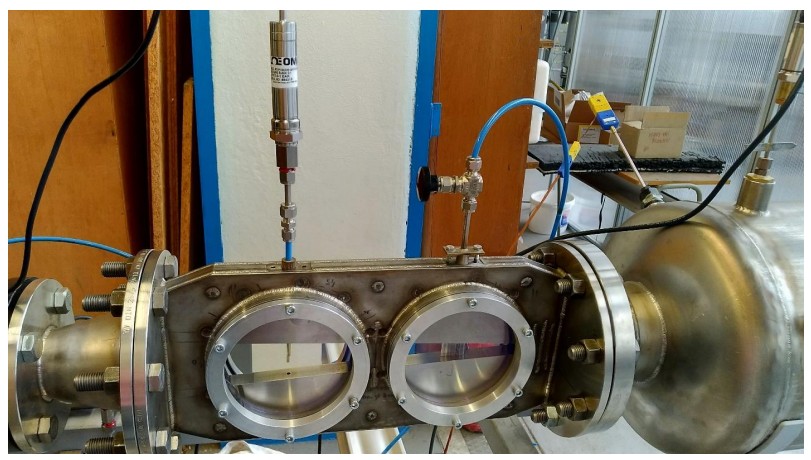

Figure 2. New wind tunnel test section.

of coarse droplets detected was very low due significantly lower number density in compare with the fine droplets and short exposure time of the light source. A photogrammetric method was implemented in the probe of the diameter $50 \mathrm{~mm}$ for the measurement in the steam turbine under operation. The diameter of the captured droplet images was around $60 \mu \mathrm{m}$. The diameter of the coarse droplets according to the Weber number (eq. 1) was expected smaller [6]. Due to difficulties connected with taking measurements in an operating steam turbine, the new wind tunnel was designed and manufactured for the analysis of the formation of coarse droplets from liquid films. The goal of the design was to model the conditions in the steam turbine as closely as possible together while maintaining the advantages of working in the laboratory.

The tunnel is designed in the shape of a typical converging-diverging nozzle (fig. 2), but the planned operational regime is subsonic or transonic. An airfoil NACA0008 is placed $50 \mathrm{~mm}$ behind the nozzle throat. The airfoil simulates a blade in a turbine and it is possible to replace it or even remove it. On the airfoil is a groove for supplying liquid on the surface. The tunnel is equipped with four large windows to provide good optical access for the measurement. Liquid is pumped to the airfoil through a dosing pump with a flow from $1 \mu \mathrm{L} / \mathrm{min}$ to $500 \mu \mathrm{L} / \mathrm{min}$. This range is

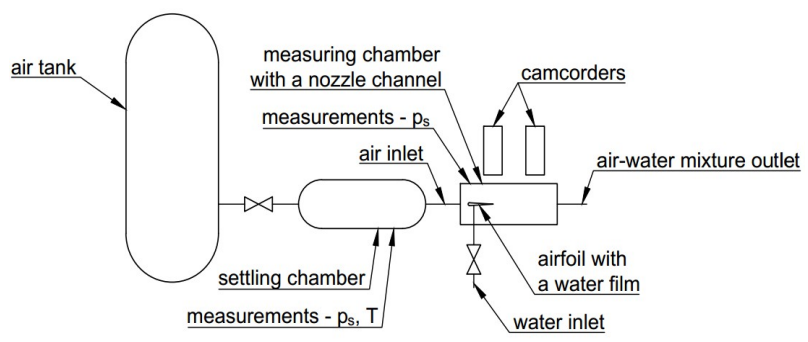

FIGURE 3. Measurement schema of the nozzle.

sufficient for the simulation of different liquid films on the airfoil. It is possible to operate the tunnel with steam in continuous flow mode or with compressed air for periodic measurements. The time duration of the measurement in the wind tunnel with air depends on the pressure in the compressor storage vessel and it is for air in range 15 to $25 \mathrm{~s}$. The pressure and temperature of the entire measurement sequence is acquired by the NI SCXI measurement system for the description of the flow condition for each measurement. Mass flow is determined by the stagnation conditions in the settling chamber and the flow blockage in the nozzle throat. The schema of the optical and flow field measurement is shown in Fig. 3

\section{INSTRUMENTATION AND MEASUREMENT}

The expected diameter of coarse droplets in steam turbines is in the range between 1 to $500 \mu \mathrm{m}$ a similar range is expected for the nozzle as well. Optical measurement of the size distribution of the droplets is commonly used. Nevertheless, the size range of the diameters of the droplets can hardly be measured with one single optical technique. For that reason the new wind tunnel is equipped with two optical methods, photogrammetry and light scattering. With sufficient overlaps, these methods can cover most of the range.

Photogrammetry is a method for determining the object properties in a photographic image. The theoretical resolution of the method is determined by the pixel pitch of the camera and the resolution of the lens. The size of the pixel pitch usually ranges from 2 to $6 \mu \mathrm{m}$ or common digital cameras. The magnification of the lens is limited by the minimum exposure time of the camera when a global shutter is used. Higher magnification can provide better resolution for smaller droplets, but the displacement of the droplets may then be greater than the size of the observed volume when the picture is taken.

The velocity of droplets can reach more than $200 \mathrm{~m} / \mathrm{s}$ in a turbine and that rate may be even higher in the nozzle. The velocities of the droplets and the minimum exposure time define the size of the observed volume. The entire observed volume must be caught on the camera sensor and this limits the magnification of the lens. This means that each droplet is represented on the picture by a line. 


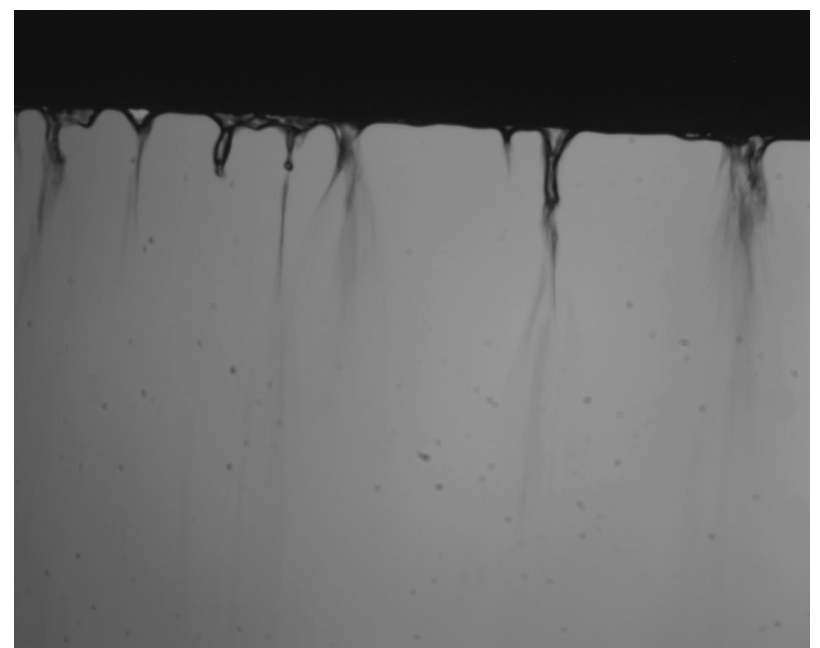

FiguRE 4. Droplets formation on the trailing edge of the profile in the wind tunnel.

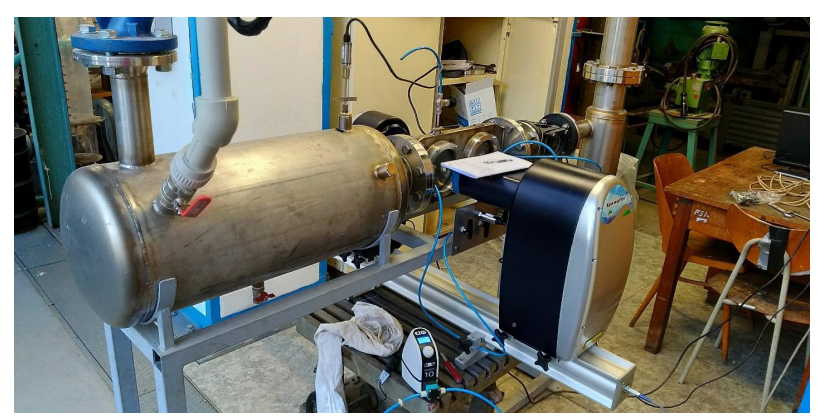

Figure 5. The Spraytec position on the wind tunnel.

Figure 4 shows an example of back-side illumination of droplet paths captured in the laboratory. The length of the path and the exposure time allows for computation of the velocity of the droplet and determines the expected direction of the droplet's movement. But it is necessary to keep in mind that the view of the motion is two-dimensional. This means that components of the velocity can only be viewed perpendicular to the axis of the camera. The depth of the observed volume is determined by the depth of field of the lens. A telecentric lens is more advantageous because the image size is independent of the distance from the lens. Calibration is required for the correct pixel/dimension ratio. A light source with the duration of the flash ranging from $5-100 \mu$ s is used.

The second method for measuring the diameter of the droplets is based on light scattering. The analyzer used is an industrial device called Spraytec produced by Malvern Instruments. The results are achieved through the use of laser light scattering. The placement of Spraytec in the wind tunnel is shown in Fig. 5 .

\section{DATA PROCESSING}

After acquiring the first measurements with the photogrammetric method and light scattering, the following knowledge was obtained. An example of the application of the photogrammetry method can be seen in fig. 4 In the picture one can see the break up of the liquid film from the airfoil. Two groups of droplets are formed from the airfoil. In the first stage bigger droplets are formed but later these break up into smaller droplets. Sometimes bigger droplets remain in the flow. The measurement stagnation condition was 3 bar and $295 \mathrm{~K}$. The smaller droplets are under the detection limit of the photogrammetry method and it wasn't possible to measure their size distribution function. The result of the analysis of the bigger droplets: mean diameter of the distributions is around $68 \mu \mathrm{m}$, Sauter mean diameter $181 \mu \mathrm{m}$.

For the measurement with the Spraytec system similar conditions were used: 3 bar, $295 \mathrm{~K}$. The flow of the demineralized water used for the atomization was $5 \mu \mathrm{L} / \mathrm{min}$. The results of the volume distribution are presented in fig. 6.

All 27 measured volume distributions have 2 significant mods with respect of the diameter. The first maximum (small droplets) was for the diameter around $10 \mu \mathrm{m}$ and bigger droplets had a mod around $600 \mu \mathrm{m}$. The velocity of air before the nozzle throat was quasiconstant during the measurement at $250 \mathrm{~m} / \mathrm{s}$ which corresponds with $\mathrm{Ma}=0.8$ for stagnant conditions and static pressure as shown on fig. 7 .

\section{Results}

A good knowledge of the flow field in the wind tunnel is necessary for the understanding of the droplets formation. The simultaneous measurement of the flow parameters during the droplets break up on the trailing edge of the aerofoil are logged, the measurement of the stagnation parameters in the settling chamber and static pressure along the nozzle profile. The velocity profile in the test section was measured at the middle of the second optical window at position of $244 \mathrm{~mm}$ (distance/throat is 16) down the nozzle throat. The measurement was done with both a Pitot probe and a probe for the measurement of the static pressure. The probes moved along the high of the channel at $4 \mathrm{~mm}$ increments. The velocity profile is shown on the fig. 8 for three different time positions after the beginning of the expansion. The total time for the measurement with the air takes $15 \mathrm{sec}$, for this reason we use three time position to see the velocity profile behaviors.

The time position was 3,5 and 8 seconds after opening the valve. The velocity profiles indicate high velocity at the measurement position and no significant flow separation on the walls.

For the assessment of the droplets formed by the gas flow atomization a Weber number is usually used. It is a dimensionless number which respects the flow inertia and surface tension of the formed droplets. The Weber number can be written as,

$$
W e=\frac{\rho_{g} w_{r}^{2} d}{\sigma}
$$




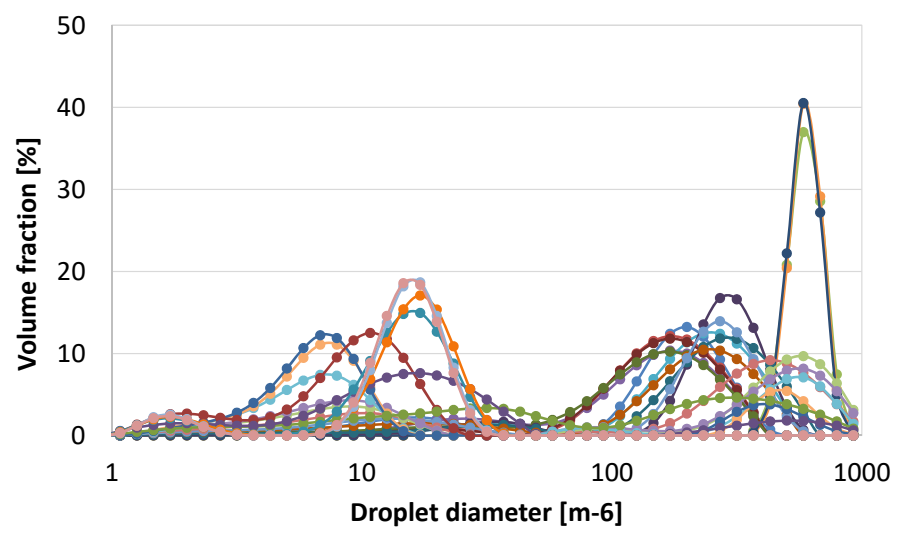

FiguRE 6. An example of the distribution function (Volume fraction) acquired by Spraytec. The figure shows volume fraction distributions for 27 different measurement. Two significant droplet diameter mods are clearly visible for all of the measurements.

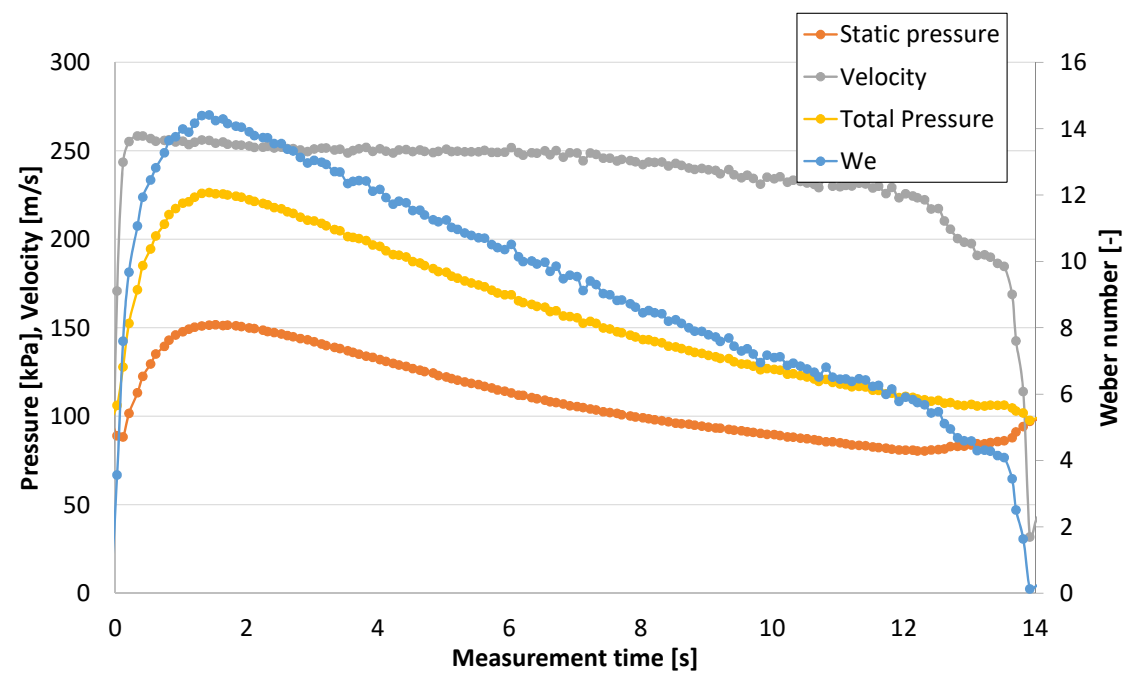

FIGURE 7. Profile of the velocity and pressures during the measurement.

where $\rho_{g}$ is the vapour density, $\sigma$ is the surface tension of water, $w_{r}$ is the relative velocity between the vapour and droplets, and $\mathrm{d}$ is the diameter of the droplets.

In previous works [6, 7] a critical Weber number was found which indicates the biggest droplet formed by the gas liquid interaction for a higher Mach number of approximately 40. The required data about the diameter of the droplets disagrees with the commonly used estimation with the Weber number. In general, the disagreement increases with the velocity. In this work new knowledge about the bi-modal distribution of the formed droplets was used for additional data processing. The data about the size distribution function was divided to two groups and for each of these the Sauter diameter was computed. The edge diameter is $60 \mu \mathrm{m}$. On the Fig. 9 the time depen- dence of the Sauter diameter of both groups acquired from the measurement with Spraytec can be observed. In the case of this measurement, the Weber number for the first group of smaller droplets is We around 5-10 and for second group of the bigger droplets the $\bmod$ is around $\mathrm{We}=500$.

\section{Conclusions}

The goal of this paper is to introduce a new facility and method of measurement, therefore only preliminary data from the measurements is available now. Systematic study of the phenomena will continue and the new tunnel has proved to be very promising for further research. The explanation and proof of the bi-modal droplet size distribution can provide new insight for the design of turbine blades. 


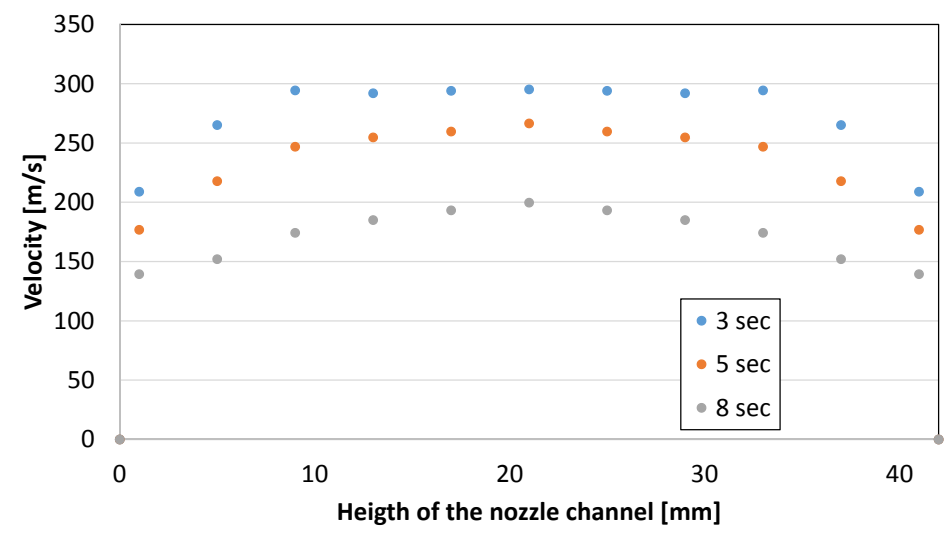

FiguRE 8. Profile of the velocity in the nozzle channel. The profile was processed for the three time position after the measurement sequence start.

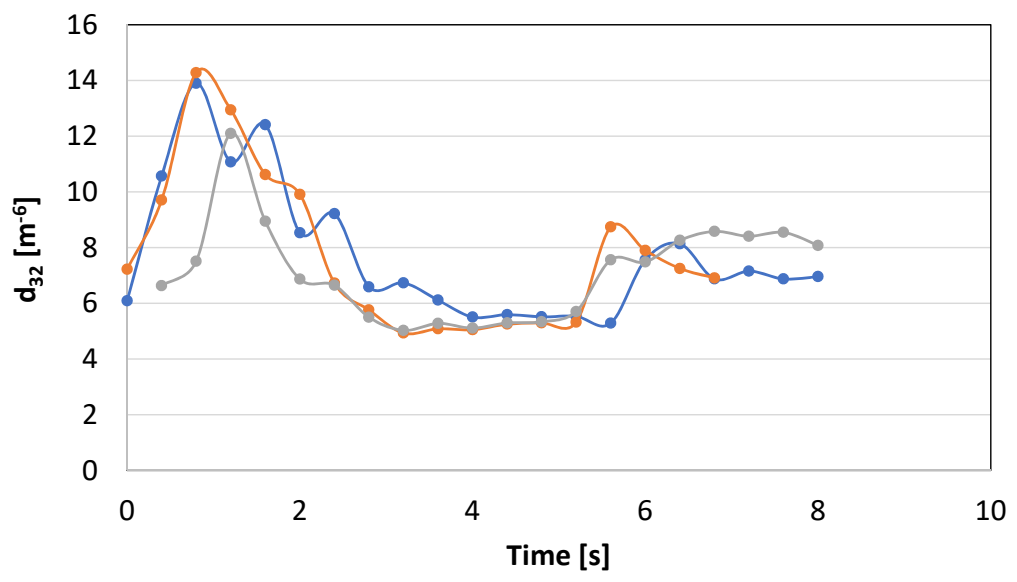

FiguRE 9. Three arbitrary time lines of the Sauter diameter.

\section{LIST OF SYMBOLS}

$d$ Droplet diameter $[\mathrm{m}]$

$w$ Velocity $[\mathrm{m} / \mathrm{s}]$

$d_{32}$ Sauter mean diameter $[\mathrm{m}]$

$\varrho_{g} \quad$ Gas density $\left[\mathrm{kg} \mathrm{m}^{-3}\right]$

$\sigma$ Surface tension $[\mathrm{N} / \mathrm{m}]$

Ma Mach number

Re Reynold's number

We Weber number

\section{ACKNOWLEDGEMENTS}

We gratefully acknowledge the support by the Grant Agency of the Czech Technical University in Prague, grant No. SGS 13/18 and Grant No. 16-20123S of the Grant Agency of the Czech Republic.

\section{REFERENCES}

[1] O. Bartoš, M. Kolovratník. Adjustment of the optical probe for the measurement in the steam turbines. In Experimental Fluid Mechanics 2009 - Conference Proceedings. Liberec, Czech Republic, 2009.

[2] O. Bartoš, X. Cai, M. Kolovratník. A detection of the coarse water droplets in steam turbines. In EPJ Web of Conferences, vol. 67. 2014.

[3] T. Sauer. Electrostatic charging of rotors. Die Wärme 59(35):575-576, 1936.

[4] P. Lenard. Ueber die Electricität der Wasserfälle. Annalen der Physik 282(8):584-636, 1892. DOI:10.1002/andp.18922820805

[5] Kolovratník, Michal, Bartoš, Ondřej. CTU Optical probes for liquid phase detection in the $1000 \mathrm{MW}$ steam turbine. EPJ Web of Conferences 92:02035, 2015. DOI:10.1051/epjconf/20159202035. 
[6] J. Valha. Proudění mokré páry a její erozivní účinky v průtočné části parní turbíny. In SVUSS, Sborník referátů. 1978.

[7] M. J. Moore, C. H. Sieverding. Two-Phase Steam

Flow in Turbines and Separators. McGraw-Hill, 1976. 